\title{
Relationship between Apgar score and umbilical cord blood acid-base balance in full-term and late preterm newborns born in medium and severe conditions
}

\author{
Marta Mlodawska ${ }^{1}$, Jakub Mlodawski ${ }^{1}\left[\right.$, Aleksandra Gladys-Jakubczyk ${ }^{2}$, \\ Grazyna Pazera² \\ ${ }^{1}$ Collegium Medicum, Jan Kochanowski University in Kielce, Kielce, Poland \\ ${ }^{2}$ Clinic of Neonatology, Provincial Combined Hospital, Kielce, Poland
}

\begin{abstract}
Objectives: Application of Apgar scores (AS) and umbilical cord blood acid-base analysis is a base for the prediction of future neurological development in children. In clinical practice we often observe huge discrepancy between clinical and biochemical status of newborn. Because many obstetricians consider both assessments as substitute and measure of their proceeding's outcome, we decided to scientifically measure actual correlation between them among newborns born with Apgar less than 8 points.

Material and methods: This was an observational retrospective study. The study included 141 newborns born in general medium and severe condition (Apgar $<8$ points in first minute of life). Acid-base analysis of umbilical cord vein blood immediately after birth was performed. We correlated gasometric parameters with Apgar scores of newborns.

Results: The clinical condition of a newborn at 1,5 , and 10 minutes after birth correlates positively and significantly with $\mathrm{pH}$ values $(0.25 ; 0.24$; and 0.26 ; respectively) and bicarbonate levels $(0.21 ; 0.27 ; 0.28$; respectively) in the umbilical cord vein, however correlation was low. Subsequently we qualified newborns to four groups depending on the degree of invasiveness of respiratory support after delivery, and the groups were compared in terms of parameters of acid-based balance. No significant differences were observed between groups in terms of acid-base balance parameters.

Conclusions: There is low, but significant correlation between clinical condition of a newborn after birth with most of acid-base parameters from umbilical vein blood. The assessment of the newborn's condition after birth using the Apgar score, (but not acid-base parameters) determines the degree of invasiveness of respiratory support activities for newborns after birth.
\end{abstract}

Key words: Apgar score; umbilical cord; gasometric parameters; moderate condition newborn; severe condition newborn

Ginekologia Polska 2022; 93, 1:57-62

\section{INTRODUCTION}

The Apgar score is a versatile and widely used assessment of the clinical condition of a newborn after birth. The Apgar score helps to identify newborns requiring further resuscitation and allows the assessment of a newborn's reflexes in a simple and fast manner [1]. However, the subjectivity of this assessment makes the Apgar score an unreliable predictive tool and assessing of the general condition of the newborn immediately after birth is burdened with high error probability [2-4]. Umbilical cord blood gasometry (UCBG) is a test that should objectively assess the condition of a baby after birth. The accuracy and reliability of tests assessing the acid-base balance in the fetus depends on the methodology of blood collection and the puncture of the appropriate umbilical cord vessel. Currently, there is no consensus among leading scientific societies in which precise clinical situations the UCBG should be performed. However, the majority recommends this study be performed in cases of increased risk of fetal metabolic acidosis, e.g., operative delivery, abnormal cardiotocography (CTG) tracing, decreased Apgar scores in newborns, prolonged second stage of labour, and uterine tachysystole during delivery $[5,6]$. The literature data indicate that the method of taking blood samples from the umbilical cord is important in achieving reliable gasometry

\footnotetext{
Corresponding author:

Marta Mlodawska

Collegium Medicum, Jan Kochanowski University in Kielce, Kielce, Poland

e-mail: mlodawska.mm@gmail.com
} 
results. Therefore, more dependable results are acquired by centers taking this test routinely in all newborns instead of only specific indications [7]. In our center, blood sampling from the umbilical cord vein for blood gas analysis testing is standard in all newborns due to easy identification of the vessel and its easy collection. In the literature, in most studies assessing the newborn's morbidity and mortality depending on the $\mathrm{pH}$, blood gas analysis was determined from arterial blood. This method has a strong physiological basis, due to blood flows in this vessel before gas exchange in the placenta from the newborn's internal iliac vessels, which better reflects the condition of the fetus. The blood flowing in the opposite direction from the placenta to the fetus through the umbilical cord vein reflects the mixed state/performance of the placenta, e.g., the acid-base balance of mother and child.

The placenta is responsible for equalizing acid-base imbalance in fetal life. Its efficiency in the case of fetal hypoxia depends on many factors (e.g., gestational age, anemia, presence of a heart defect). During an uncomplicated physiological delivery, the average value of base excess $(B E)$ is no more than $-5 \mathrm{mmol} / \mathrm{L}$ and a change of $3 \mathrm{mmol} / \mathrm{L}$ requires regular uterine contractions for several hours. In the case of complicated labor, the situation is different. In repeated moderate decelerations of the fetal pulse rate, the $1 \mathrm{mmol} / \mathrm{L}$ reduction of $\mathrm{BE}$ takes place after approximately 30 minutes. In the case of severe bradycardia, the $1 \mathrm{mmol} / \mathrm{L}$ reduction of $\mathrm{BE}$ takes place after two to three minutes [8]. During the interpretation of UCBG both values are important: $\mathrm{pH}$ and $\mathrm{BE}$ value, which allow to distinguish respiratory and metabolic acidosis.

Apgar scores, as well as UCBG are commonly considered as distinct tools for prediction of future neurological development in children, which carry the same important clinical information about the condition of the newborn after birth. Obstetricians, considering the subjectivity of the Apgar scale, often use cord blood gas analysis as measures of their proceeding's outcome, marginalizing the assessment of the fetal clinical condition. The aim of this study was to investigate the actual correlation between Apgar scores and umbilical cord blood gas analysis results in the group of newborns born in moderate and severe clinical conditions. The analysis of the clinical condition of this newborns' group is often the subject of discussion and disagreement between obstetricians and neonatologists.

\section{MATERIAL AND METHODS}

This observational retrospective study included 141 newborns from single pregnancies at the gestational age of 35 weeks and above born with $\leq 7$ points of Apgar score at 1 minute of life, what means born in moderate and severe condition, in whom no malformation was found.
The Apgar test was done at 1, 5 and 10 minutes by neonatologists of the unit. All births took place in the Department of Obstetrics and Gynecology of the Provincial Combined Hospital in Kielce from 01.01.2018 to 30.06.2019. Number of patients included in study were estimated a priori based on power calculation of estimated correlation (80\%). We retrieved preliminary data from similar study results [9]. The study was retrospective and medical records were analyzed. Gestation period was confirmed by embryo biometry in the first trimester of pregnancy, and in case of discrepancies $>7$ days corrected. In all cases, blood from the umbilical cord vein was collected immediately after the umbilical cord was clamped for gas analysis, using the ABL800FLEX. In order to limit the influence of immaturity on the clinical condition of the newborn after birth, all newborn babies born before 35 weeks gestation were excluded from the study. Also, we excluded newborns with birth defects and those where we did not obtain a complete blood gas analysis from the umbilical cord vein. The analysis of Apgar score correlation at 1,5, and 10 minutes of life with the parameters of acid-base balance of newborns was performed. Next, newborns were divided into one of four groups depending on the degree of invasiveness of management supporting the respiratory process in newborns within the first $15 \mathrm{~min}$ utes after birth: Group I — children not requiring respiratory support, in whom only dry and wrap management was used, Group II - children requiring only continuous positive airway pressure (CPAP), Group III — children requiring lung recruitment, positive pressure ventilation or intubation with mechanical ventilation, and Group IV — children requiring cardiopulmonary resuscitation. Acid-base balance parameters were then compared among the groups. Statistical analyses were performed using Statistica 13.1 (Tibco Software Inc). Arithmetic means and standard deviations were used to describe the examined groups, in the case of skewness distributions the median and $25^{\text {th }}$ and $75^{\text {th }}$ percentile or interquartile ranges were used as a measure of central tendency. Qualitative data was presented as a percentage. Because the assumption of normal distribution was not met Spearman's rank correlation was used to investigate if a relationship existed. Continuous variables between groups were compared using Kruskal-Wallis test. Differences were considered significant in case of $\mathrm{p}<0.05$.

\section{RESULTS}

Data from one hundred and forty-one newborns was analyzed. Tables 1 and 2 present the characteristics of the study group. An analysis of the correlation of Apgar score at 1, 5 and 10 minutes of life with the acid-base balance parameters of the newborn was performed. Table 3 presents correlation coefficients with probability values. A significant positive correlation of $\mathrm{pH}[0.25(\mathrm{p}=0.002) ; 0.24(\mathrm{p}=0.002)$; 
Table 1. Baseline characteristics of study group

\begin{tabular}{|l|l|l|l|}
\hline Parameter & & & \\
\hline Delivery $(n ; \%)$ & $1^{\text {st }}(87 ; 61.7 \%)$ & $2^{\text {nd }}(41 ; 29 \%)$ & $3^{\text {rd }}$ and more $(13 ; 9.2 \%)$ \\
\hline Mode of delivery & vaginal delivery $(60 ; 42.5 \%)$ & vacum extraction $(5 ; 3.5 \%)$ & cesarean section $(76 ; 53.9 \%)$ \\
\hline Gestational age & $<37$ weeks $(16 ; 11.3 \%)$ & $\geq 37$ weeks $(125 ; 88.7 \%)$ & \\
\hline $1^{\text {st }}$ minute Apgar score & $4-7$ points $(138 ; 97.8 \%)$ & $0-3$ points $(3 ; 2.2 \%)$ & \\
\hline $5^{\text {th }}$ minute Apgar score & $8-10$ points $(100 ; 70.9 \%)$ & $4-7$ points $(40 ; 28.3 \%)$ & $0-3$ points $(1 ; 0.7 \%)$ \\
\hline $10^{\text {th }}$ minute Apgar score & $8-10$ points $(128 ; 90.7 \%)$ & $4-7$ points $(12 ; 8.5 \%)$ & $0-3$ points $(1 ; 0.7 \%)$ \\
\hline $\mathrm{pH}(\mathrm{n} ; \%)$ & $<7.0(1 ; 0.7 \%)$ & $<7.1(6 ; 4.25 \%)$ & $<7.2(29 ; 20.5 \%)$ \\
\hline $\mathrm{BE}(\mathrm{n} ; \%)$ & $<-12(8 ; 5.67 \%)$ & $<-16(1 ; 0.7 \%)$ & \\
\hline $\mathrm{BE}$ & & & \\
\hline
\end{tabular}

$\mathrm{BE}$ - base excess

Table 2. Quantitative characteristics of study group

\begin{tabular}{|l|l|}
\hline Parameter & Mean $(+/-S D)$ \\
\hline Mother's age & $32.4 \mathrm{y}(6.2 \mathrm{y})$ \\
\hline Newborn weight & $3327 \mathrm{~g}(577 \mathrm{~g})$ \\
\hline & median $\left(25^{\text {th }}-75^{\text {th }}\right.$ percentile $)$ \\
\hline $\mathrm{pH}$ & $7.28(7.22-7.36)$ \\
\hline $\mathrm{pCO} 2[\mathrm{mmHg}]$ & $45.97(38.3-51.7)$ \\
\hline $\mathrm{BE}[\mathrm{mmol} / \mathrm{L}]$ & $-4.49(-6.8-(-1.8))$ \\
\hline $\mathrm{HCO} 3-[\mathrm{mmol} / \mathrm{L}]$ & $18.84(16.3-21.4)$ \\
\hline
\end{tabular}

$0.26(p=0.001)$; respectively] and bicarbonate concentration [0.21 $(p=0.009) ; 0.27(p=0.001) ; 0.28(p=0.000)$; respectively] with clinical status (Apgar scores) at 1,5, and 10 minutes of life was observed. A positive correlation of base excess [0.26 ( $p=0.001) ; 0.26(p=0.001)$; respectively] and Apgar scores at 5 and 10 minutes of life and a negative correlation of carbon dioxide partial pressure $[-0.18(p=0.03)]$ with an Apgar score at 1 minute of life was also seen. In every case, correlation was low. The management with each newborn after birth was consistent with the ERC 2015 recommendations [10]. Eighty-two newborns were qualified to Group I (58\%), 27 were qualified to Group II (19\%), 32 newborns in Group III (22\%), and Group IV (1\%) included 2 children. The parameters of acid-base balance between particular groups of newborns were compared. No statistically significant differences between these groups were found. The results of the study are presented in Table 4.

\section{DISCUSSION}

Clinical assessment of a newborn after birth using the Apgar score is very important because it identifies those that require the implementation of resuscitation procedures. As shown in this study, it is the clinical condition,

Table 3. Correlation coefficients of Apgar score with the acid-base balance parameters (with probability values)

\begin{tabular}{|l|l|l|l}
\hline Parametars & Apgar $\mathbf{1}^{\text {st }}$ minute & Apgar $5^{\text {th }}$ minute & Apgar $\mathbf{1 0}^{\text {th }}$ minute \\
\hline $\mathrm{pH}$ & $0.25(p=0.002)$ & $0.24(p=0.002)$ & $0.26(p=0.001)$ \\
\hline $\mathrm{pCO} 2[\mathrm{mmHg}]$ & $-0,18(p=0.03)$ & $-0.07(p=0.4)$ & $-0.11(p=0.18)$ \\
\hline $\mathrm{BE}[\mathrm{mmol} / \mathrm{L}]$ & $0.16(p=0.05)$ & $0.26(p=0.001)$ & $0.26(p=0.001)$ \\
\hline HCO3-[mmol/L] & $0.21(p=0.009)$ & $0.27(p=0.001)$ & $0.28(p=0.000)$
\end{tabular}

$\mathrm{BE}$ - base excess

Table 4. Comparison the parameters of acid-base balance between particular groups of newborns

\begin{tabular}{|l|l|l|l|l|l|}
\hline ERC group & $\mathbf{1}$ & $\mathbf{2}$ & $\mathbf{3}$ & $\mathbf{4}$ \\
\hline Number of cases & $37(26 \%)$ & $22(16 \%)$ & $80(57 \%)$ & $2(1 \%)$ \\
\hline $\mathrm{pH}(\mathrm{IQR})$ & $7.27(0.17)$ & $7.3(0.11)$ & $7.32(0.14)$ & $7.28(\mathrm{~N} / \mathrm{A})$ \\
\hline $\mathrm{pCO} 2[\mathrm{mmHg}](\mathrm{IQR})$ & $43.7(18.9)$ & $42.25(11.8)$ & $44.75(11.3)$ & $48.55(\mathrm{~N} / \mathrm{A})$ \\
\hline $\mathrm{BE}[\mathrm{mmol} / \mathrm{L}](\mathrm{IQR})$ & $-5.8(5.3)$ & $-4.35(6.9)$ & $-2.9(4.27)$ & $-2.8(\mathrm{~N} / \mathrm{A})$ & $\mathrm{p}=0.72$ \\
\hline $\mathrm{HCO}-[\mathrm{mmol} / \mathrm{L}](\mathrm{IQR})$ & $18.4(4.3)$ & $19.05(4.5)$ & $20.2(4.1)$ & $20.25(\mathrm{~N} / \mathrm{A})$ & $\mathrm{p}=0.28$ \\
\hline
\end{tabular}

IQR - interquartile range 
not the results of the UCBG, which determines the degree of invasiveness of intervention in newborns immediately after birth. The results of the study showed that the groups of patients with different degrees of invasive procedures did not differ in terms of the values of umbilical cord blood analysis parameters (Tab. 4). In literature there are many studies demonstrating association of low Apgar scores with increased risks of neonatal and infant death and with neurologic disability, however, the absolute risks for Apgar score $<7$, are low ( $<5 \%$ in for most neurologic conditions) and majority of surviving babies with low Apgar scores grow up without disability [11]. A population-based cohort study of the 150081 children shows continuously increasing risks of developmental vulnerability and special needs at 5 years of age with decreasing $1 \mathrm{~min}$ and $5 \mathrm{~min}$ Apgar scores [12]. The Risks of cerebral palsy and epilepsy are inversely associated with 5 minute and 10 minutes Apgar scores across the entire range of Apgar scores [13]. On the other hand the decreased Apgar score should not confirm serious abnormalities in the fetus, but may be a result, for example, of the temporary action of analgesic drugs administered to the mother during labour. The correct Apgar score does not exclude the possibility of adverse outcome in the newborn. In literature there are reports of higher morbidity and mortality in children born with an Apgar score of 7, 8 or 9 versus 10 points [14] and a higher risk of physical disorders [adjusted odds ratio (aOR) for Apgar $9=1.23,95 \% \mathrm{Cl} 1.05-1.44$ ] and emotional disorders (aOR for Apgar $9=1.20,95 \% \mathrm{Cl} 1.03-1.41$ ) in 5 years of children's age full-term neonates born at the time of delivery with an Apgar score $\leq 9$ points at 5 minutes of life in comparison with children born at 10 points [15]. As a result of the above findings, The American College of Obstetricians and Gynecologists states, the Apgar scale cannot be used to predict neonatal mortality and neurological consequences in the future. The subjective Apgar score cannot be the only marker of clinical condition used to diagnose perinatal asphyxia [2-4].

UBCG is widely recognized as a source of objective information of fetal well-being. A key role in obtaining a reliable $\mathrm{pH}$ result for a cord blood sample is acquired by the method of sampling, the location of the umbilical cord puncture site, and the correct operation of the blood gas analyzer. According to some authors, in certain clinical situations, the probability of incomplete (UCBG) may increase, e.g., situations with Apgar scores $<7$ [odds ratio (OR) 1.68, 95\% Cl 1.29-2.19], cesarean section (OR 1.31, $95 \% \mathrm{Cl} 1.11-1.55$ ) or multiple pregnancies (OR 2.02, 95\% Cl 1.69-2.43) [16]. The causes mentioned above may be the reason for discrepancies between the clinical condition and blood gas parameters of the acid-base balance. In our center, blood sampling from umbilical cord is being taken in each newborn. Due to easy identification of the vessel and its easy collection we assessed blood gas analysis from the umbilical cord vein. In the systematic review and meta-analysis of 2010, five studies assessing venous blood gas analysis met the inclusion criteria. The meta-analysis showed significant association with neonatal morbidity (OR 4.0, 1.2-13.3, $12=44.5 \%$ ) for the assessment of the $\mathrm{pH}$ of blood collected from the umbilical cord vein [17]. The median difference between the vein and the umbilical artery is 0.09 . In the case of simultaneous vascular puncture, the difference ranged from $0.02-0.45$, median difference BE was $0.8 \mathrm{mmol} / \mathrm{L}$ [18]. In $18 \%$ of the cases in the study mentioned above, the sample was taken from a different vessel than intended, which was secondary to the blood gas analysis results from individual samples. Having such a high percentage of cases proves that the puncture of the umbilical cord vessel, particularly the artery, is a procedure with a high error probability. Due to the large diameter of the vessel, blood collection from the umbilical cord vein is technically easier than from the umbilical artery. The blood gas parameters of venous cord blood are characterized by high predictive capacity in the detection of arterial $\mathrm{pH}<7$ [area under the curve (AUC) $0.95595 \% \mathrm{Cl} 0.946-0.964$ ] [19]. BE from the vein was also characterized by high predictive capacity of $B E \leq-12$ in the arterial vessel ( $A U C=0.961,95 \%$ $\mathrm{Cl} 0.963-0.971)$. If the $\mathrm{pH}$ value of blood collected from the umbilical cord vein is $\geq 7.16$, the risk of neonatal acidosis is lower than $5 \%$ [19].

The results of published studies unequivocally indicate the case of an uncomplicated physiological delivery, the $\mathrm{pH}$ of blood collected from the umbilical cord vein compared to blood collected from the umbilical cord artery is $7.35+/-0.05$ vs $7.28+/-0.05$, respectively (arithmetic mean $+/-$ standard deviation) [20]. If the dispersion at the level of two standard deviations is considered normal in laboratory tests, the normal pH (reference) values can be 7.25-7.45 for venous blood and 7.18-7.38 for arterial blood.

The $\mathrm{pH}$ value alone (determining the level of acidosis) is not a good prognostic factor in relation to further child development; for the distinction is crucial how long the hypoxia lasted and whether we are dealing with only respiratory acidosis (BE within normal range) or metabolic acidosis $(B E \leq-12 \mathrm{mmol} / \mathrm{L})$, which is more severe in consequences [21]. The value of base deficit, increasing with the accumulation of organic acids, correlates with increased mortality and morbidity in the future [22]. BE in the range of -12 to $-16 \mathrm{mmol} / \mathrm{L}$ is associated with an increased risk of mortality, moderate to severe encephalopathy, multi-organ failure and future neurological deficits. Such consequences are involved in $10 \%$ of newborns with umbilical artery base deficit (BD) in the range of 12 to $16 \mathrm{mmol} / \mathrm{L}$ and in $40 \%$ of those with a BD $>16 \mathrm{mmol} / \mathrm{L}[23,24]$. Metabolic acidosis, according to the International Cerebral Palsy Task Force, is 
defined as a $\mathrm{pH}$ in umbilical cord blood gas analysis $<7$ and $\mathrm{BE}<-12 \mathrm{mmol} / \mathrm{L}$ [25]. The cut-off points for diagnosis were originally identified based on the consensus of a working group supported by scientific pediatric and obstetric societies from seven countries rather than on high quality scientific evidence. However, the subsequent meta-analysis of 51 studies [17] which combined the result of arterial umbilical cord blood gas analysis with measures of compromise of neonatal or childhood well-being indicated an increased risk of morbidity and mortality at higher $\mathrm{pH}$ values $(\mathrm{pH}<7.2)$ [17]. A pH $<7.2$ increased both infant mortality $(\mathrm{OR}=4.3$, $95 \% \mathrm{Cl} ; 2.2-8.7$, in 5 studies) and morbidity (hypo-ischemic encephalopathy, seizures, paraventricular leukomalacia, mechanical ventilation, intraventricular hemorrhage, and abnormal neurological examination) $(\mathrm{OR}=2.2,95 \% \mathrm{Cl}$; 1.3-3.7) [26]. Many children born with acidosis may not develop neurological complications in the future. On the other hand, most children with cerebral palsy are born with umbilical cord blood gas analysis within a normal range, as the etiology of this disease is very complex [27].

Acidosis in newborns has complicated about $1-2 \%$ of births, but it is believed that it should not be of much importance in newborns with good clinical standing. However, in one retrospective study, which recruited children with scores of 7 or more on the Apgar scale at 5 minutes of life, it was shown that in the group of children with acidosis $(\mathrm{pH} \leq 7.1$ from the umbilical artery) the complications are more frequent than in children with a $\mathrm{pH}>7.1$ in the blood gas analysis. Statistically significant differences were found in the incidence of respiratory distress syndrome (RDS) [aOR 4.6, (95\% Cl 3.1-6.85)], meconium aspiration syndrome (MAS) [aOR 2.43, (95\% Cl 1.3-4.53)], and hospitalization in neonatal intensive care unit (NICU) [aOR $3.68(95 \% \mathrm{Cl}$ 2.81-4.82)]. Additionally, in the group of examined children, obtaining a $B E$ value $\leq 10 \mathrm{mmol} / \mathrm{L}$ from the umbilical cord artery compared to a $B E$ value $>-10 \mathrm{mmol} / \mathrm{L}$ was also associated with a statistically increased number of complications: MAS [aOR 2.67, (95\% Cl 1.57-4.53)], necessity of hospitalization in NICU [aOR 2.33, (95\% Cl 1.77-3.07)], and development of neonatal sepsis [aOR 3.13, $(95 \% \mathrm{Cl}$ 1.56-6.25)] [7]. In our group of patients, only one neonate fulfilled the arbitrary criteria of acidosis, which was associated with the moderate clinical condition according to the Apgar scale (6 points). The vast majority of newborns in our study group (79.5\%) had a pH higher than 7.2. In our group of patients there are low but statistically significant correlation between clinical condition of a newborn after birth with most of acid-base parameters from umbilical vein blood. This low correlation emphasizes that these both methods are not substitutes and the combined interpretation of Apgar score results and umbilical cord venous blood gas sample is more useful in the assessment of the condition of the newborn after birth than the interpretation of the results of these tests separately.

The limitation of our study may be due to the lack of lactate concentration determination in the obtained samples. This study is not routinely performed in our center, as the available literature points to poor predictive value of this determination in relation to the further occurrence of complications in newborns.

\section{CONCLUSIONS}

1. The combined interpretation of Apgar score results and umbilical cord venous blood gas sample is more useful in the assessment of the condition of the newborn after birth than the interpretation of the results of these tests independently.

2. There is low correlation between clinical condition of a newborn after birth with most of acid-base parameters from umbilical vein blood.

3. The evaluation of a newborn after birth using the Apgar score is a main factor, which determines the degree of invasiveness of respiratory support activities for newborns after birth.

\section{Data Availability}

The datasets generated and/or analysed during the current study are available in the public repository, DOI 10.17605/OSF.IO/HYNPK.

\section{Acknowledgments}

Project financed under the program of the Minister of Science and Higher Education under the name "Regional Initiative of Excellence in 2019-2022" project number: 024/RID/2018/19, financing amount: 11,999,000.00 PLN.

\section{Conflict of interest}

All authors declare no conflict of interest.

\section{REFERENCES}

1. Chamberlain G, Banks J. Assessment of the Apgar score. Lancet. 1974 2(7891): 1225-1228, doi: 10.1016/s0140-6736(74)90745-4, indexed in Pubmed: 4139469.

2. American academy of pediatrics committee on fetus and newborn american college of obstetricians and gynecologists committee on obstetric practice. The Apgar score. Pediatrics. 2015; 136(4): 819-822, doi: 10.1542/peds.2015-2651, indexed in Pubmed: 26416932.

3. Simon LV, Hashmi MF, Bragg BN. APGAR score. StatPearls [Internet]. 2021, indexed in Pubmed: 29262097.

4. Montgomery KS. Apgar scores: examining the long-term significance. J Perinat Educ. 2000; 9(3): 5-9, doi: 10.1624/105812400X87716, indexed in Pubmed: 17273212.

5. Ayres-de-Campos D, Arulkumaran S, et al. FIGO Intrapartum Fetal Monitoring Expert Consensus Panel. FIGO consensus quidelines on intrapartum fetal monitoring: Physiology of fetal oxygenation and the main goals of intrapartum fetal monitoring. Int J Gynaecol Obstet. 2015; 131(1): 5-8, doi: 10.1016/j.ijgo.2015.06.018, indexed in Pubmed: 26433399.

6. ACOG Committee on Obstetric Practice. ACOG Committee Opinion No. 348, November 2006: Umbilical cord blood gas and acid-base analy- 
sis. Obstet Gynecol. 2006; 108(5): 1319-1322, doi: 10.1097/00006250200611000-00058, indexed in Pubmed: 17077266.

7. Sabol BA, Caughey AB. Acidemia in neonates with a 5-minute Apgar score of 7 or greater - What are the outcomes? Am J Obstet Gynecol. 2016; 215(4): 486.e1-486.e6, doi: 10.1016/j.ajog.2016.05.035, indexed in Pubmed: 27255470.

8. Swanson K, Whelan AR, Grobman WA, et al. Can venous cord gas values predict fetal acidemia? Am J Obstet Gynecol. 2017; 217(3): 364.e1-364. e5, doi: 10.1016/j.ajog.2017.05.047, indexed in Pubmed: 28578170.

9. Ahmadpour-Kacho M, Asnafi N, Javadian M, et al. Correlation between umbilical cord pH and apgar score in high-risk pregnancy. Iran J Pediatr. 2010; 20(4): 401-406, indexed in Pubmed: 23056738.

10. Wyllie J, Bruinenberg J, Roehr CC, et al. European resuscitation council guidelines for resuscitation 2015: Section 7. Resuscitation and support of transition of babies at birth. Resuscitation. 2015; 95: 249-263, doi: 10.1016/j.resuscitation.2015.07.029, indexed in Pubmed: 26477415.

11. Ehrenstein V. Association of Apgar scores with death and neurologic disability. Clin Epidemiol. 2009; 1:45-53, doi: 10.2147/clep.s4782, indexed in Pubmed: 20865086.

12. Razaz N, Cnattingius S, Persson M, et al. One-minute and five-minute Apgar scores and child developmental health at 5 years of age: a population-based cohort study in British Columbia, Canada. BMJ Open. 2019; 9(5): e027655, doi: 10.1136/bmjopen-2018-027655, indexed in Pubmed: 31072859.

13. Persson M, Razaz N, Tedroff $K$, et al. Five and 10 minute Apgar scores and risks of cerebral palsy and epilepsy: population based cohort study in Sweden. BMJ. 2018; 360: k207, doi: 10.1136/bmj.k207, indexed in Pubmed: 29437691.

14. Razaz N, Cnattingius S, Joseph KS. Association between Apgar scores of 7 to 9 and neonatal mortality and morbidity: population based cohort study of term infants in Sweden. BMJ. 2019; 365: I1656, doi: 10.1136/bmj. I1656, indexed in Pubmed: 31064770.

15. Razaz N, Boyce WT, Brownell M, et al. Five-minute Apgar score as a marker for developmental vulnerability at 5 years of age. Arch Dis Child Fetal Neonatal Ed. 2016; 101(2): F114-F120, doi: 10.1136/archdischild-2015-308458, indexed in Pubmed: 26187935.

16. van Tetering AAC, van de Ven J, Fransen AF, et al. Risk factors of incomplete Apgar score and umbilical cord blood gas analysis: a retrospective observational study. J Matern Fetal Neonatal Med. 2017; 30(21): 2539-2544, doi: 10.1080/14767058.2016.1256985, indexed in Pubmed: 27884069.
17. Malin GL, Morris RK, Khan KS. Strength of association between umbilical cord $\mathrm{pH}$ and perinatal and long term outcomes: systematic review and meta-analysis. BMJ. 2010; 340: c1471, doi: 10.1136/bmj.c1471, indexed in Pubmed: 20466789.

18. Westgate J, Garibaldi JM, Greene KR. Umbilical cord blood gas analysis at delivery: a time for quality data. Br J Obstet Gynaecol. 1994; 101(12): 1054-1063, doi: 10.1111/j.1471-0528.1994.tb13581.x, indexed in Pubmed: 7826958.

19. Yeomans ER, Hauth JC, Gilstrap LC, et al. Umbilical cord pH, PCO2, and bicarbonate following uncomplicated term vaginal deliveries. Am J Obstet Gynecol. 1985; 151(6): 798-800, doi: 10.1016/0002-9378(85)90523-x, indexed in Pubmed: 3919587.

20. Ross MG, Gala R. Use of umbilical artery base excess: algorithm for the timing of hypoxic injury. Am J Obstet Gynecol. 2002; 187(1): 1-9, doi: 10.1067/mob.2002.123204, indexed in Pubmed: 12114881.

21. Cunningham FG, Leveno K, Bloom S, Hauth JC, Rouse DJ, Spong CY Williams Obstetrics: 23rd edition. The McGraw-Hill Education / Medical 2009: 595-598.

22. American College of Obstetricians and Gynecologists, American Academy of Pediatrics. Neonatal encephalopathy and neurologic outcome, Second Edition. Washington 2014.

23. Low JA, Lindsay BG, Derrick EJ. Threshold of metabolic acidosis associated with newborn complications. Am J Obstet Gynecol. 1997; 177(6): 1391-1394, doi: 10.1016/s0002-9378(97)70080-2, indexed in Pubmed: 9423740.

24. Low JA. Determining the contribution of asphyxia to brain damage in the neonate. J Obstet Gynaecol Res. 2004; 30(4): 276-286, doi: 10.1111/j. 1447-0756.2004.00194.x, indexed in Pubmed: 15238103.

25. MacLennan A. A template for defining a causal relation between acute intrapartum events and cerebral palsy: international consensus statement. BMJ. 1999; 319(7216): 1054-1059, doi: 10.1136/bmj.319.7216.1054, indexed in Pubmed: 10521205.

26. Executive summary: neonatal encephalopathy and neurologic outcome, second ediction. Report of the american college of obstetricians and gynecologists' task force on neonatal encephalopathy. Obset Gynecol. 2014; 123(4): 896-901.

27. Mlodawski J, Mlodawska M, Pazera G, et al. Cerebral palsy and obstetric-neonatological interventions. Ginekol Pol. 2019; 90(12): 722-727, doi: 10.5603/GP.2019.0124, indexed in Pubmed: 31909467. 